\title{
Laboreal
}

Volume 13 NN$^{\circ} 2$ | 2017

Varia

\section{Os fatores psicossociais de risco na atividade de tecnicos superiores de segurança no trabalho}

Los factores de riesgo psicosociales en la actividad de los técnicos superiores de seguridad en el trabajo

Les facteurs psychosociaux de risque dans l'activité des techniciens supérieurs de sécurité au travail

The psychosocial risk factors in the activity of the advanced technicians on occupational health

\section{Joana F. Ramalho e Lúcia Simões Costa}

\section{(2) OpenEdition}

\section{Journals}

Edição electrónica

URL: http://journals.openedition.org/laboreal/359

DOI: $10.4000 /$ laboreal.359

ISSN: 1646-5237

\section{Editora}

Universidade do Porto

\section{Refêrencia eletrónica}

Joana F. Ramalho e Lúcia Simões Costa, « Os fatores psicossociais de risco na atividade de tecnicos superiores de segurança no trabalho », Laboreal [Online], Volume $13 \mathrm{~N}^{0} 2$ | 2017, posto online no dia 0 dezembro 2017, consultado o 07 outubro 2019. URL : http://journals.openedition.org/laboreal/359 ; DOI : 10.4000/laboreal.359

Este documento foi criado de forma automática no dia 7 outubro 2019

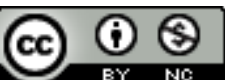

Laboreal está licenciado com uma Licença Creative Commons - Atribuição-NãoComercial 4.0 Internacional. 


\section{Os fatores psicossociais de risco na atividade de tecnicos superiores de segurança no trabalho}

Los factores de riesgo psicosociales en la actividad de los técnicos superiores de seguridad en el trabajo

Les facteurs psychosociaux de risque dans l'activité des techniciens supérieurs de sécurité au travail

The psychosocial risk factors in the activity of the advanced technicians on occupational health

Joana F. Ramalho e Lúcia Simões Costa

\section{NOTA DO EDITOR}

http://dx.doi.org/10.15667/laborealxiii0217jr

Manuscrito recebido em: setembro/2017

Aceite após peritagem: novembro/2017

\section{As transformações na organização do trabalho e os fatores psicossociais de risco}

1 O trabalho é um elemento fundamental na vida de um indivíduo, quer por ser uma fonte de rendimento, quer por ter um efeito regulador na sua vida social, sendo muitas vezes desempenhado num ambiente repleto de dimensões que afetam a saúde física e mental do trabalhador (Carvalho, 2009).

Os efeitos da crise que se tem vivido, a introdução de novas tecnologias e as mudanças sociais e organizacionais trouxeram profundas transformações, podendo gerar, no local 
de trabalho, dinâmicas de cariz psicossocial que se tornam, não raras vezes, preocupantes (Rocha, 2012; Amaro, 2013).

3 De modo a manterem-se competitivas, as empresas investem, com efeito, em novas formas de utilização de mão-de-obra (Coelho, 2009). A procura pelo aumento de produtividade encontra-se, então, aliada à redução do número de trabalhadores, à pressão de tempo, ao aumento da complexidade das tarefas, ao aumento da mobilização cognitiva, do ritmo, da responsabilidade e dos horários diferenciados - expondo quem trabalha a situações desgastantes. Esta evolução, apontada como uma das causas mais prováveis no que se refere ao absentismo laboral, está relacionada com problemas de saúde, como alterações músculo-esqueléticas ou doenças cardiovasculares, esgotamentos profissionais ou transtornos de saúde mental. Mas, por outro lado, e paradoxalmente, surgem igualmente consequências negativas para as organizações, como a diminuição do seu rendimento, podendo o ambiente de trabalho ser ainda mais afetado, o que inclui os relacionamentos com os superiores e os colegas (Coelho, 2009).

A prevalência dos ditos "riscos psicossociais" no trabalho emerge neste contexto tendo, os mesmos, origem nas condições de trabalho com prejuízos óbvios para a evolução do estado de saúde, mental, físico e social (Gollac \& Bodier, 2011). Os fatores que aqui interferem são variados, frequentemente imprecisos, podem ocorrer em qualquer contexto e nem sempre é fácil de prever que danos podem provocar e a que nível (Costa, 2013). Acresce que os trabalhadores não são passivos em relação ao seu ambiente de trabalho e à possibilidade de gerir estes fatores, podendo, assim, reagir e, às vezes, conseguir modificar o seu ambiente (Costa, 2013). A questão da metodologia para o seu diagnóstico constitui em consequência um desafio capital.

Entre as várias técnicas para avaliação dos riscos profissionais, existem metodologias ditas objetivas e outras que apostam na subjetividade, isto é, na autoavaliação dos próprios trabalhadores (Ferreira, 2015). Algumas focam-se, principalmente, na identificação das consequências para a saúde do trabalhador, em vez de procurarem distinguir os fatores que estão na sua origem. Ora, os "riscos psicossociais" resultam de um conjunto de condições e de fatores intrínsecos à organização do trabalho, e são esses que devem ser identificados por via de uma análise das condições de trabalho, dos fatores organizacionais e relacionais (Costa, 2013). Por outro lado, apesar da notoriedade que estas questões têm adquirido, o esforço até agora feito, nomeadamente em Portugal, não se tem traduzido em resultados muito conclusivos na prevenção - o que, de acordo com Coelho (2009), pode ser justificado pelo fosso que existe entre a legislação vigente e a prática efetiva desta mesma prevenção, admitindo que este problema existe na maioria das empresas da União Europeia (UE).

\section{A emergência da profissão do técnico superior de segurança no trabalho na legislação portuguesa e a análise das condições em que trabalha}

\section{1. evolução da legislação portuguesa em matéria de SST}

6 Os temas relativos à Segurança e Saúde no Trabalho (SST) têm despertado preocupações constantes, tanto por parte dos tra- balhadores, como por parte do 
Estado e, consequentemente, por parte das empresas, advindo, principalmente, da tomada de consciência quanto às más condições que se faziam sentir.

Podemos lembrar que tal tomada de consciência emergiu no decorrer do processo de industrialização, acarretando situações de miséria e degradação das condições de vida dos trabalhadores e seus familiares. Registamos, assim, em Portugal as primeiras preocupações neste campo na segunda metade do Séc. XIX, numa altura em que as obras públicas de estradas, portos e caminhos-de-ferro estavam no seu auge. Aliás, em 1855 é promulgado um decreto que procurou regulamentar a atividade industrial no que refere à Higiene, Segurança e Salubridade, impondo nomeadamente o licenciamento dos estabelecimentos que conferissem perigosidade para a saúde das populações circundantes. Note-se que estas questões ganharam mais relevância em 1867 após a aprovação e publicação do primeiro código civil português (Cosme, 2006).

8 Nesses anos iniciou-se o que Graça (2002) nomeou "a protohistória da legislação laboral", estendendo-se depois ao período da República (1910-1926), à fase da Ditadura Militar (1926-1933) e aos primeiros anos do Estado Novo (1933-1949). Por exemplo, só em 1913 é que é promulgada legislação sobre a reparação dos acidentes de trabalho e só em 1936 surge o conceito e a figura jurídica de "doenças profissionais" (Graça, 2002).

$\mathrm{Na}$ verdade, a legislação substancial nesta matéria resultou essencialmente da inserção de Portugal em dinâmicas, económicas e políticas, internacionais.

Assim, a internacionalização da economia portuguesa está, sem dúvida, em pano de fundo do Decreto-Lei $\mathrm{n}^{\mathrm{0}} 44308$, de 27 de abril de 1962, que tornou obrigatória a organização de serviços médicos do trabalho nas minas, nos estabelecimentos industriais e noutros locais de trabalho em que existisse o risco de silicose - sendo alargado em 1967 a todas as empresas, independentemente da existência do risco de silicose. Nesta conjuntura, é de realçar também aqui o Decreto no 45 992, de 23 de outubro de 1964 pelo facto de ter previsto a inserção, em tais serviços, de técnicos de outras profissões ("engenheiros, químicos, enfermeiros e porventura outros", Graça, 2002).

11 Mas é a integração europeia de Portugal em 1986 que será decisiva nesta evolução. 0 Decreto-Lei $n^{\circ}$ 441/91, de 14 de novembro formaliza o enquadramento nacional da segurança e saúde no trabalho, dando cumprimento às obrigações decorrentes da Convenção $\mathrm{n}^{\circ} 155$ da OIT e transpondo para a ordem jurídica interna o quadro normativo da Directiva 89/391/CEE (Assembleia da República, 1993).

Desde aí, outras regulamentações adjacentes surgiram, das quais se destaca o DecretoLei $\mathrm{n}^{\mathrm{0}}$ 110/2000, de 30 de junho, que estabeleceu as condições de acesso e exercício da profissão de Técnico Superior de Segurança e Higiene do Trabalho, bem como a, subalterna, de Técnico de Segurança e Higiene do Trabalho, e ainda as normas específicas para a homologação dos respetivos cursos de formação profissional. Estes diplomas foram preponderantes para que a SST fosse incorporada no contexto das empresas, pois contribuíram para a definição de um quadro referencial na organização dos serviços de SST e no seu exercício profissional.

13 A consolidação do regime jurídico de SST em Portugal foi plenamente alcançada com a aprovação do novo Código do Trabalho, inicialmente em 2003 e, mais recentemente em 2009, já contando neste momento com várias alterações e retificações. 
E é de referir aqui a Lei $n^{\circ} 42 / 2012$, de 28 de agosto, que confirma o Técnico Superior de Segurança no Trabalho (TSST) como o "profissional que organiza, desenvolve, coordena e controla as atividades de prevenção e de proteção contra riscos profissionais".

\subsection{0 trabalho prescrito e a atividade real do Técnico Superior de Segurança no Trabalho em Portugal}

15 Nesta profissão, criada pela legislação acima referida, destacam-se as atividades seguintes (IDICT, 2001):

- Colaborar na elaboração da política geral da empresa em matéria de prevenção dos riscos e no planeamento e implementação do correspondente sistema de gestão;

- Elaborar avaliações de risco;

- Desenvolver medidas de prevenção e de proteção, garantindo a sua adequação;

- Coordenar tecnicamente as atividades de SST, assegurando o enquadramento e a orientação de outros profissionais da área da SST;

- Participar na organização do trabalho;

- Gerir os recursos externos necessários às atividades de prevenção e de proteção;

- Manter organizada a documentação necessária à gestão da prevenção na empresa;

- Assegurar a informação e a formação dos trabalhadores e de outros intervenientes nos locais de trabalho da empresa;

- Promover a consulta e participação dos trabalhadores;

- Promover a integração da prevenção nos sistemas de comunicação da empresa;

- Desenvolver as relações da empresa com os organismos da Rede Nacional de Prevenção de Riscos Profissionais.

E, como em todas as profissões, também a profissão de TSST deve ser desenvolvida tendo em conta alguns princípios deontológicos. São eles (Decreto-Lei nº 110/2000 de 30 de junho):

- Considerar a SST como uma prioridade na sua intervenção;

- Atuar com base em conhecimentos científicos e com competência técnica, solicitando sempre a intervenção de peritos especializados quando for necessário;

- Adquirir e manter a competência necessária no exercício das funções;

- Executar as funções com autonomia técnica, colaborando com o empregador no cumprimento das obrigações legais;

- Informar os trabalhadores e seus representantes nesta matéria assim como o empregador, sobre situações particularmente perigosas que necessitem de uma intervenção urgente;

- Cooperar com os trabalhadores e os representantes, fomentando a sua intervenção proativa sobre os fatores de risco profissional nomeadamente quanto às medidas de prevenção a implementar e/ou implementadas;

- Não revelar questões ligadas à empresa, como segredos de fabricação, comércio e de exploração, que tenha conhecimento;

- Manter confidenciais todos os dados que afetem a privacidade dos trabalhadores;

- Consultar e cooperar com os organismos nacionais ligados à prevenção de riscos profissionais.

17 Todavia, se os TSST atuam na prevenção e promoção da saúde dos trabalhadores identificando e avaliando os riscos a que eles estão expostos e sugerindo medidas que reduzam o nível de exposição e respetivas consequências, farão o mesmo por si pró 
prios? Será que o foco destes profissionais está tão virado para os trabalhadores da sua responsabilidade que acabam por deixar a própria saúde para segundo plano?

Inoue \& Vilela (2014), no Brasil, admitiram que, se as entidades fiscalizadoras em matéria de SST se direcionam aos trabalhadores da linha de produção das empresas, os seus próprios técnicos acabam por não ser contemplados por essas preocupações e intervenções (Inoue \& Vilela, 2014).

A pesquisa que realizaram a partir desta constatação inicial, centrada na atividade de profissionais dos Serviços Especializados em Engenharia de Segurança e Medicina do Trabalho (SESMT), apresenta o interesse de dar acesso às vivências dos tais técnicos no desenvolvimento das suas funções. Neste caso, a falta de poder decisório, de autonomia, que os autores associam ao conceito de "poder de agir" de Yves Clot (2010) referido em Inoue \& Vilela (2014), mostra-se não somente um elemento limitante da prática profissional, mas revela-se sobretudo determinante nos sentimentos de ansiedade, insatisfação e "adoecimento psíquico", resultantes do desempenho de uma atividade constantemente em "contraposição entre as determinações legais e as prescrições das empresas contratantes" (Inoue \& Vilela, 2014, p. 139).

Não são numerosos os estudos nesta matéria, mas pode referir-se Peeters et al. (2003) quando apresentaram um estudo franco-brasileiro cujo objetivo tinha sido de identificar, através da caraterização da atividade profissional da segurança no trabalho, os aspetos que podem ser melhorados nos cursos de formação profissional. Indicaram na altura algumas opiniões por parte dos inquiridos brasileiros como, já, a falta de participação nas tomadas de decisão, mas ainda: a dificuldade em sensibilizar os trabalhadores, o facto de grande parte da jornada de trabalho ser dedicada às tarefas administrativas e burocráticas, e, nas empresas, a falta de reconhecimento profissional (Peeters, et al., 2003). Por corresponder a uma linha de pesquisa em constante desenvolvimento (Garrigou \& Peissel-Cottenaz, 2013) é de lembrar igualmente as investigações que, desde o fim dos anos 90 , foram orientadas para a compreensão das dificuldades metodológicas que este tipo de profissional enfrenta na procura de soluções dos problemas encontrados nos seus locais de intervenção. Assim, Garrigou et al. (1999), num estudo comparativo das caraterísticas da atividade de profissionais de segurança, em França e no Quebec, realçaram a complexidade do seu posicionamento face aos vários modelos de análise valorizados nas organizações (factor humano Vs fator técnico; modelo de avaliação de riscos reduzido aos riscos vísiveis; entre outros), à tensão entre esses modelos, as suas contradições e os obstáculos às abordagens mais inovadoras (Garrigou, et al., 1999). A literatura nesta matéria, embora parca, ilustra sem dúvida um campo de pesquisa promissor - que tentámos destrinçar em Portugal com o estudo apresentado a seguir.

\section{Os objetivos e a metodologia do estudo}

O estudo que aqui iremos sintetizar teve como objetivo principal verificar se os TSST que desempenham a sua atividade em Portugal estão ou não expostos a condições de trabalho adversas, eventualmente atravessadas por fatores psicossociais de risco - e se acabam, em consequência, por ver deteriorado o estado da sua saúde.

Optámos por privilegiar uma abordagem do tipo descritivo-correlacional, com vista a avançar numa primeira interpretação dos fenómenos em jogo. A conceção do desenho 
amostral ficou então estabelecida pela adoção do princípio de uma amostragem não probabilística, recorrendo à técnica da solicitação acidental ou por conveniência, perfazendo deste modo a um total de 101 inquiridos.

Os dados obtidos foram recolhidos com o recurso a um inquérito de autoavaliação disponibilizado online em formato editável, em grupos de técnicos de segurança no trabalho contactados pela via de algumas entidades ligadas a esta área profissional. Recorremos ao inquérito INSAT - Inquérito Saúde e Trabalho 2013 de Barros, Cunha e Lacomblez pelo seu perfil epidemiológico e por ter como objetivo "compreender de que forma os trabalhadores avaliam as caraterísticas e as condições do seu trabalho, o seu estado de saúde e que tipo de relações estabelece entre a saúde e o seu trabalho" (Rocha, 2012). É, todavia, de realçar, desde já, que o instrumento não foi concebido para tal uso, mas sim como suporte de um diálogo entre analista e trabalhador na elaboração conjunta de um diagnóstico.

O INSAT encontra-se organizado em sete eixos: I - O trabalho; II - Condições e caraterísticas do trabalho; III - Condições de vida fora do trabalho; IV - Formação e trabalho; V - Saúde e o trabalho; VI - A minha saúde e o meu trabalho; e VII - A minha saúde e o meu bem-estar. Na maioria das questões analisadas, as respostas são constituídas por duas partes. Na primeira, pretende-se obter uma resposta sim/ não, e na segunda, a quantificação do grau de incómodo (muito incómodo, bastante incómodo, incómodo, pouco incómodo e nenhum incómodo) numa escala de Likert de 5 pontos, sendo que quanto menor for a pontuação mais incómodo o inquirido sente.

Para melhor se perceber os resultados apresentados a seguir, é importante indicar ainda que se entendeu que o indivíduo estaria incomodado quando assinalasse "muito incómodo", "bastante incómodo" ou "incómodo", respetivamente 1, 2 e 3 de pontuação, e por outro lado, que não estaria incomodado quando assinalasse "pouco incómodo" ou "nenhum incómodo", respetivamente 4 e 5 de pontuação. Assim, quando a média obtida relativa ao grau de incómodo for inferior a 3,5, considera-se que o indivíduo se sente incomodado, e não incomodado se esta for superior ou igual a 3,5. Os inquiridos foram devidamente informados, nomeadamente quanto ao objetivo principal deste estudo e à confidencialidade dos dados.

\section{Apresentação e discussão dos resultados}

\subsection{Caraterização da Amostra}

26 A maioria dos participantes deste estudo é do sexo feminino ( 36 homens e 61 mulheres) sendo que a média de idades ronda os 37 anos. São, na sua maioria, casados, não têm filhos e os respetivos companheiros estão empregados. Quanto aos aspetos laborais, a maioria trabalha em médias empresas, do setor privado, por conta de outrem e têm contratos sem termo. Têm, em média, oito anos de experiência na profissão e de antiguidade na empresa. São maioritariamente técnicos internos das empresas ou comuns, e desenvolvem funções por conta de outrem. 


\subsection{Exposição e Incómodo a Condições e Caraterísticas do} Trabalho

O eixo do INSAT consagrado às Condições e Caraterísticas do Trabalho apresenta itens relacionados com as dimensões ambientais. Neste plano, a maioria dos inquiridos revela não estar exposta aos mesmos, sendo que o item com percentagem mais elevada é a exposição a temperaturas extremas (48,5\%). Note-se que muitos dos inquiridos desenvolvem a sua atividade em empresas de construção.

Quanto aos Constrangimentos Físicos, o único item a que a maioria indicou estar exposto diz respeito a permanecer muito tempo sentado (70,3\%), o que revela que boa parte da jornada de trabalho dos inquiridos é passada no escritório. Para alargar a nossa compreensão da atividade dos TSST, convém completá-la com a identificação dos fatores psicossociais de risco suscetíveis de interferir na sua atividade. São então apresentadas na Tabela 1 as situações mais indicadas pelos inquiridos de acordo com as dimensões do INSAT.

Tabela 1: Condições e caraterísticas de trabalho

\begin{tabular}{|c|c|c|}
\hline \multicolumn{3}{|l|}{ Exposição } \\
\hline \multicolumn{3}{|l|}{ CONDIÇÕES E CARATERÍSTICAS DE TRABALHO } \\
\hline & $\operatorname{Sim} n(\%)$ & Não n (\%) \\
\hline \multicolumn{3}{|l|}{ RÍTMO DE TRABALHO } \\
\hline Ritmo intenso & $59(58,4)$ & $42(41,6)$ \\
\hline Cumprir normas de produção ou prazos rígidos & $57(56,4)$ & $42(41,6)$ \\
\hline Trabalhar muito tempo ao computador & $87(86,1)$ & $14(13,9)$ \\
\hline Frequentes interrupções & $58(57,4)$ & $43(42,6)$ \\
\hline Manter olhar fixo sobre o trabalho & $10(9,9)$ & $91(90,1)$ \\
\hline \multicolumn{3}{|l|}{ TEMPO DE TRABALHO } \\
\hline Ultrapassar o horário normal & $63(62,4)$ & $38(37,6)$ \\
\hline Horários que obrigam a levantar antes 5 horas da manhã & $7(6,9)$ & $94(93,1)$ \\
\hline Manter disponibilidade permanente & $43(42,6)$ & $58(57,4)$ \\
\hline Fazer deslocações profissionais frequentes & $39(38,6)$ & $61(60,4)$ \\
\hline \multicolumn{3}{|l|}{ AUTONOMIA E INICIATIVA NO TRABALHO } \\
\hline Obrigado a respeitar de forma rígida as pausas & $10(9,9)$ & $91(90,1)$ \\
\hline Obedecer a um horário de trabalho rígido & $10(9,9)$ & $91(90,1)$ \\
\hline
\end{tabular}




\begin{tabular}{|c|c|c|}
\hline Não poder participar nas decisões relativas ao meu trabalho & $17(16,8)$ & $84(83,2)$ \\
\hline \multicolumn{3}{|l|}{ RELAÇÕES DE TRABALHO } \\
\hline Necessidade de ajuda dos colegas & $46(45,5)$ & $55(54,5)$ \\
\hline Pouco reconhecimento pelas chefias & $40(39,6)$ & $61(60,4)$ \\
\hline Agressão física & $2(2,0)$ & $98(97,0)$ \\
\hline Assédio sexual & $2(2,0)$ & $98(97,0)$ \\
\hline \multicolumn{3}{|l|}{ CONTATO COM O PÚBLICO } \\
\hline Contato direto com o público & $68(67,3)$ & $33(32,7)$ \\
\hline Suportar as exigências do público & $54(53,5)$ & $13(12,8)$ \\
\hline Confronto com situações de tensão nas relações com o público & $47(46,5)$ & $20(19,8)$ \\
\hline Agressão física do público & $17(16,8)$ & $50(49,5)$ \\
\hline \multicolumn{3}{|l|}{ CARATERÍSTICAS DO TRABALHO } \\
\hline Variado & $83(82,1)$ & $15(14,9)$ \\
\hline Imprevisível & $69(68,3)$ & $32(31,7)$ \\
\hline Complexo & $75(74,3)$ & $26(25,7)$ \\
\hline Não existe perspetiva de evolução na carreira & $54(53,5)$ & $47(46,5)$ \\
\hline Cuja remuneração não permite ter um nível de vida satisfatório & $54(53,5)$ & $47(46,5)$ \\
\hline Cujas condições abalam a minha dignidade & $8(7,9)$ & $91(90,1)$ \\
\hline
\end{tabular}

Como se pode observar na Tabela 1 relativamente às condições em termos de Ritmo de Trabalho, trabalhar muito tempo ao computador foi o item com maior percentagem de exposição $(86,1 \%)$. Por outro lado, o que causa mais incómodo é o facto de serem frequentemente interrompidos, o que também se verificou nos estudos realizados por Carvalho (2009) e Rocha (2012).

30 Na dimensão Tempo de Trabalho, os inquiridos revelaram, maioritariamente, terem de ultrapassar o horário normal. Já o item que lhes causava mais incómodo era ter que dormir a horas pouco usuais, mas poucos inquiridos indicaram estar expostos a esta situação. A situação na qual menos inquiridos referem estar expostos diz respeito a ter horários de trabalho que obrigam a levantar antes das 5 horas da manhã (6,9\%).

31 As questões inseridas na categoria Autonomia e Iniciativa no Trabalho, não parecem ser fonte de especial constrangimento, sendo, ainda assim, a situação mais referida o não poder participar nas decisões relativas ao seu trabalho (16,8\%), e as menos referidas o facto de ser obrigado a respeitar de forma rígida as pausas e o ter de obedecer a um horário de trabalho rígido, ambas com 9,9\% de exposição. Embora esta seja a dimensão 
à qual os inquiridos revelam estar menos expostos, é aquela em que a perceção do incómodo é maior, o que pode querer significar que quando não existe autonomia, tal é percecionado como um forte constrangimento para a realização da atividade de trabalho.

De notar que a condição de trabalho a que os indivíduos indicam estar mais expostos é também aquela que lhes causa mais incómodo, ou seja, "não poder participar nas decisões relativas ao seu trabalho". Com efeito, apesar da autonomia técnica destes profissionais, é possível que, em muitas relações laborais, principalmente no caso em que os TSST se encontram internos às empresas, as tomadas de decisão não sejam, em último caso, da responsabilidade ou passíveis de ser assumidas pelo técnico. Esta situação pode verificar-se, nomeadamente, quando os TSST identificam situações potencialmente perigosas para os trabalhadores, mas cuja resolução implica autorização superior.

33 Ainda nesta dimensão, mais de metade da amostra revelou não estar exposta a ter que respeitar de forma rígida as pausas e a ter de obedecer a um horário de trabalho rígido, usufruindo possivelmente de flexibilidade horária.

34 A maioria dos participantes não indicou estar exposto aos itens que referem Relações de Trabalho problemáticas. E, embora $45,5 \%$ tenha referido a necessidade de ajuda de colegas, tal parece ser uma situação que não constitui elevado constrangimento. Contudo, em relação ao pouco reconhecimento do seu trabalho pelas chefias, se o mesmo não é apontado, não deixa de ser causa de incómodo. Tal, vai de encontro aos resultados do estudo de Inoue \& Vilela (2014), no qual os TSST criticam a invisibilidade do seu trabalho. De facto, muitas vezes parece que os TSST são contratados apenas para dar cumprimento às imposições legais, verificando-se depois da sua contratação disparidades entre as funções exigidas na Lei e a política interna das empresas, não sendo também dado valor ao conhecimento, desempenho e às vantagens que os TSST podem trazer para as organizações (Inoue \& Vilela, 2014). Evitar os acidentes de trabalho recorrendo à análise das situações de trabalho, implementar medidas preventivas, partilhar formação e informação, parece não acarretar lucro direto às empresas e daí, tal como é referido por Inoue e Vilela (2014), o técnico ser muitas vezes considerado um "limitador de produção".

35 A maioria dos inquiridos $(67,3 \%)$ refere ter contato direto com o público - isto é, os clientes e os trabalhadores das empresas onde prestam serviço - sendo que é a agressão verbal que mais os incomoda. Os TSST lidam na maior parte das vezes diretamente com os trabalhadores, ouvindo e percebendo as situações que os incomodam e que, na opinião destes, mereciam uma intervenção; mas também é destes técnicos que se espera a formação e informação dos trabalhadores sobre as questões de segurança envolvidas na forma como realizam as suas funções, incluindo o uso de Equipamentos de Proteção Coletiva (EPC) e de EPI; equipamentos esses que nem sempre são compatíveis com a experiência e modos operatórios dos trabalhadores, pelo que estes podem, em determinadas situações, não perder a oportunidade de verbalizar as dificuldades e inconvenientes no seu uso já que interferem no desenvolvimento das suas atividades (Duarte, Théry \& Ullilen, 2016).

Quanto às Caraterísticas do Trabalho, mais de $50 \%$ dos inquiridos afirma que o seu trabalho é variado, complexo e imprevisível - parecendo valorizar e apreciar a diversidade de situações a analisar, a evolução destas ao longo do tempo e o confronto com a imprevisibilidade imposta pelo real. 
37 Mais problemático é o facto do seu trabalho se caraterizar pela inexistência de perspetivas de evolução na carreira e de uma remuneração que não permite ter um nível de vida satisfatório. Se estes resultados são coincidentes com a problemática social e económica da vida das empresas e do País nos últimos anos, não é de desprezar o facto destes profissionais terem responsabilidades legais e criminais, principalmente em caso de acidente de trabalho grave, considerando então a sua relação salarial sem correspondência com o conflito que se pode gerar entre o que o TSST deve e o que lhe permitem fazer. Voltamos a encontrar aqui a fonte de uma vivência de sentimentos de ansiedade e possível insatisfação, podendo levar ao "adoecimento psíquico" realçado por Inoue e Vilela (2014).

No questionário aplicado estavam presentes algumas questões onde os inquiridos puderam expor a sua perceção quanto à sua Satisfação e Realização Pessoal ${ }^{1}$. Verifica-se que, em média, os inquiridos demonstram sentimentos positivos em relação ao trabalho que realizam, onde o nível de concordância é maior no item "sentimento de fazer um trabalho bem feito" $(M=1,58)$. Apesar de concordarem que o que fazem constitui um contributo útil para a sociedade, este item é o que apresenta um menor nível de concordância.

Assim sendo, embora a maioria dos inquiridos considere a sua profissão mal remunerada, sem perspetiva de evolução e que o seu trabalho não é reconhecido pelas chefias, manifesta realização e satisfação profissional, admitindo que consegue contribuir de modo útil para a sociedade. Esta situação vai ao encontro do referido no estudo de Inoue e Vilela (2014), onde os técnicos referem que aquilo que os motiva e lhes proporciona prazer no trabalho é a perspetiva de participar na introdução de mudanças na organização do trabalho.

De referir aqui que os participantes admitiram trabalhar na sua empresa principal, em média, mais tempo do que o estipulado por lei, situação que vai ao encontro do assinalado no estudo de Inoue e Vilela (2014), e ainda nos últimos dados do Inquérito Europeu sobre as Condições de Trabalho (2010), onde se verificou que $24,6 \%$ dos trabalhadores portugueses trabalhavam mais do que as 40 horas legalmente instituídas (Costa \& Santos, 2013).

41 Finalmente, pareceu-nos interessante apresentar os resultados quanto à exposição e incómodo médio em cada uma das dimensões (Tabela 2), cuja análise conjuntamente com os dados já expostos permite perceber melhor em que condições os TSST desempenham a sua atividade, e o grau de interferência dos fatores psicossociais de risco.

Tabela 2: Exposição e Incómodo médio em cada dimensão

\begin{tabular}{|l|l|l|l|}
\hline Dimensão & \% Exposição & Média & Desvio Padrão \\
\hline Ambiente & 23,3 & 3,08 & 0,781 \\
\hline Constrangimentos Físicos & 22,0 & 3,14 & 0,870 \\
\hline Ritmo de Trabalho & 43,3 & 2,96 & 0,764 \\
\hline Tempo de Trabalho & 29,7 & 3,02 & 0,963 \\
\hline
\end{tabular}




\begin{tabular}{|l|l|l|l|}
\hline Autonomia e Iniciativa no Trabalho & 11,9 & 2,81 & 1,172 \\
\hline Relações de Trabalho & 16,0 & 3,14 & 1,245 \\
\hline Contato com o Público & 43,1 & 3,36 & 0,900 \\
\hline Características do Trabalho & 39,8 & 3,24 & 1,046 \\
\hline Satisfação e Realização pessoal & --- & 1,72 & 0,577 \\
\hline
\end{tabular}

42 As dimensões onde a percentagem de exposição dos inquiridos é, em média, maior são: o Ritmo de Trabalho e o Contacto com o Público. Pode verificar-se ainda que, em todas as dimensões, os inquiridos apontam sentir-se incomodados por elas $(M<3,5)$, sendo aquelas onde o grau de incómodo se revelou maior as dimensões Autonomia e Iniciativa no Trabalho e Ritmo de Trabalho. A dimensão Contato com o Público foi a que, embora provocando incómodo, obteve um valor inferior quando comparado com as restantes dimensões. Relativamente à Satisfação e Realização Pessoal no Trabalho, verificou-se que, em média, como já o realçámos, os inquiridos se sentem satisfeitos e realizados profissionalmente ${ }^{2}$.

Dando, então, resposta ao principal objetivo deste estudo verificou-se que uma grande percentagem de TSST indica estar exposta a condições de trabalho nas quais interferem de forma adversa fatores psicossociais de risco.

Os fatores psicossociais de risco a que os TSST estão expostos estão maioritariamente associados ao Ritmo de Trabalho, nomeadamente a um ritmo intenso de trabalho, a cumprir normas de produção ou prazos rígidos, a trabalhar muito tempo ao computador e a ser frequentemente interrompido. Estão, também, expostos aos fatores Tempo de Trabalho e Contato com o Público, sobretudo, a ultrapassar o horário normal de trabalho e a suportar as exigências do público, respetivamente. Por fim, em termos de Caraterísticas do Trabalho, o facto de não existir perspetiva de evolução na carreira e desenvolver um trabalho cuja remuneração não permite ter um nível de vida satisfatório, foram as situações identificadas como causadoras de maior constrangimento para estes profissionais.

\subsection{Estado de Saúde, Problemas de Saúde e sua Relação com o}

\section{Trabalho}

Quanto aos problemas de saúde que os TSST mais identificam, salientam-se aqueles que a maioria dos inquiridos referenciou: dores nas costas $(57,4 \%)$ e problemas de visão (50,5\%). As dores de cabeça e os problemas de ansiedade ou irritabilidade foram ambos indicados por $46,5 \%$ dos TSST. As dores de cabeça e nas costas, os problemas de visão e as dores musculares e nas articulações foram considerados, por quase metade dos inquiridos, como sendo agravados ou acelerados pelo trabalho. 
Tabela 3: 0 trabalho e a saúde na perspetiva dos TSST

\begin{tabular}{|l|l|l|l|}
\hline & $\begin{array}{l}\text { Sim, Forma positiva n } \\
(\%)\end{array}$ & $\begin{array}{l}\text { Sim, } \\
\text { Forma Negativa na } \\
(\%)\end{array}$ & $\begin{array}{l}\text { Não, de Todo n } \\
(\%)\end{array}$ \\
\hline $\begin{array}{l}\text { O trabalho afeta a minha saú } \\
\text { de }\end{array}$ & $9(8,9)$ & $32(31,7)$ & $59(58,4)$ \\
\hline & $\mathrm{n}$ & Média & Desvio Padrão \\
\hline Como está a minha saúde & 99 & 2,16 & 0,634 \\
\hline
\end{tabular}

Pretendia-se perceber qual era perceção do estado de saúde relacionado com o trabalho dos inquiridos. Os dados acima apresentados (Tabela 3) revelam que estes consideram ter uma boa saúde e julgam que a mesma é pouco afetada pelo trabalho, o que pode ser explicado pelo facto de serem trabalhadores jovens tanto em idade como em experiência profissional. Tal como em outros estudos sobre profissionais da prevenção (Garrigou et al., 1999), apesar desta perceção globalmente positiva, verifica-se que alguns desses profissionais não deixam de ver o seu trabalho como afetando a sua saúde negativamente. Relativamente aos problemas de saúde causados pelo trabalho, foram referidos o desânimo, a ansiedade ou irritabilidade e a fadiga. Factos já realçados noutras pesquisas.

\subsection{A Influência de Algumas Variáveis no Incómodo Percebido e na Perceção do Estado de Saúde}

Para ir mais adiante nesta análise, verificámos a existência de relações entre as dimensões relacionadas com fatores psicossociais e a perceção do estado de saúde, correlacionando o incómodo médio em cada dimensão com a referida perceção. Os resultados são apresentados na Tabela 4 .

Conforme a tabela anterior, existe uma correlação estatisticamente significativa entre a perceção do estado de saúde e todas as dimensões $(p<0,05)$, com exceção da Autonomia e Iniciativa no Trabalho e Satisfação e Realização Pessoal.

Tabela 4: Correlação entre o incómodo nas diferentes dimensões e a perceção do estado de saúde

\begin{tabular}{|c|c|c|c|}
\hline \multicolumn{4}{|l|}{ Perceção do estado de Saúde } \\
\hline \multicolumn{4}{|l|}{ Dimensões } \\
\hline & $\mathrm{r}$ & $p$ & $\mathrm{n}$ \\
\hline Ambiente & $-0,247^{*}$ & 0,046 & 68 \\
\hline Constrangimentos Físicos & $-0,274 *$ & 0,021 & 71 \\
\hline
\end{tabular}




\begin{tabular}{|l|l|l|l|}
\hline Ritmo de Trabalho & $-0,338^{* *}$ & 0,001 & 91 \\
\hline Tempo de Trabalho & $-0,427 * *$ & 0,000 & 71 \\
\hline Autonomia e Iniciativa no Trabalho & $-0,231$ & 0,302 & 22 \\
\hline Relações de Trabalho & $-0,323 * *$ & 0,007 & 69 \\
\hline Contato com o Público & $-0,379 * *$ & 0,002 & 62 \\
\hline Caraterísticas do Trabalho & $-0,404 * *$ & 0,000 & 91 \\
\hline Satisfação e Realização Pessoal & 0,156 & 0,126 & 98 \\
\hline * Correlação significativa ao nível 0,05; ** Correlação significativa ao nível 0,01 \\
\hline
\end{tabular}
menor é o incómodo percebido nas dimensões relativas às condições em que se trabalha, melhor é a perceção que têm sobre o seu estado de saúde. Por fim, pretendeuse verificar se o grau de incómodo estava relacionado com algumas variáveis sociodemográficas e profissionais. Para tal compararam-se as médias de incómodo obtidas e o estado de saúde percebido com as variáveis sexo, idade, estado civil, situação profissional do cônjuge, existência de filhos, localização geográfica da empresa, tamanho da empresa, situação laboral do inquirido, tipo de empresa, atividade principal, antiguidade na empresa e na profissão, tipo de funções do TSST e autonomia no desempenho da sua atividade.

Realçando aqui os resultados de maior interesse considerando a finalidade da pesquisa refere-se que, quanto às comparações com as variáveis sexo, idade, localização geográfica da empresa ${ }^{4}$, tipo de empresa, tipo de funções dos TSST $^{5}$ e autonomia no desempenho, verificou-se que os resultados não foram estatisticamente significativos $(p>0,05)$. Por outro lado, o tamanho da empresa onde cada inquirido trabalha parece influenciar o grau de incómodo nas diferentes dimensões e a perceção do estado de saúde. Verificou-se um efeito significativo desta variável sobre a dimensão Autonomia e Iniciativa $(p<0,05)$ sendo que as diferenças estatísticas se situam, segundo o teste de Tuckey, em empresas com o número de trabalhadores entre 50 e 249 (médias empresas) e com mais de 249 trabalhadores (grandes empresas). O incómodo é, então, maior nos trabalhadores que trabalham em grandes empresas. A atividade de trabalho e o que é esperado dos TSST pode efetivamente ser muito distinta em função das empresas em que se inserem, das políticas de saúde e segurança que preconizam e da margem de manobra que conferem a estes profissionais (Garrigou \& Peissel-Cottenaz, 2013). Em empresas maiores, com mais trabalhadores sob responsabilidade do TSST, vigora certamente a necessidade de uma maior vigilância sobre os potenciais efeitos das condições e da organização do trabalho. A amplitude hierárquica é também maior nestas empresas, o que pode levar a que o técnico tenha menos controlo sobre as suas funções e sobre a possibilidade real de intervenção nas situações de trabalho.

Quanto ao vínculo profissional, consideraram-se apenas as opções "Efetivo ou contrato sem termo" e "Contrato a prazo ou contrato a termo", uma vez que as respostas às 
restantes opções foram residuais. Aqui verificou-se que a média do grau de incómodo relativo aos itens da dimensão Relações de Trabalho está relacionado com a situação laboral do inquirido $(p<0,01)$, sendo que este incómodo é maior pelo facto dos inquiridos terem um contrato de trabalho a termo. A situação de emprego está, então, de algum modo a determinar a forma como se estruturam as relações de trabalho, nomeadamente pela necessidade que provavelmente sentem em demonstrar a qualidade do seu contributo para que o seu vínculo contratual não corra o risco de cessar. Os trabalhadores com vínculos permanentes provavelmente não sentem, de forma tão explícita e permanente, tal necessidade (Duarte, 2011).

\section{Conclusões e perspetivas}

52 Através dos resultados obtidos foi possível perceber que os TSST estão expostos a fatores psicossociais de risco associados a condições e caraterísticas do trabalho. Muitos destes profissionais estão expostos a um ritmo intenso de trabalho, têm de cumprir normas de produção ou prazos rígidos e acabam por ser frequentemente interrompidos. Ultrapassam o horário normal de trabalho e suportam dificilmente as exigências do público. Em termos de Caraterísticas do Trabalho, a não existência de perspetiva de evolução na carreira e o facto de desenvolverem um trabalho cuja remuneração não permite ter um nível de vida satisfatório, são situações que se podem, também, entender como interferindo de modo negativo na relação com a atividade desses profissionais. Quanto ao estado de saúde dos inquiridos face ao trabalho, conclui-se que a sua saúde é percecionada no momento atual como sendo boa e como não estando muito relacionada com o trabalho. No entanto alguns dos problemas de saúde dos TSST são considerados como sendo agravados pelo trabalho. E sobretudo: quanto menos afetados são os TSST pelos fatores psicossociais de risco, melhor percecionam a sua saúde.

Embora tendo respondido aos principais objetivos propostos, há neste estudo algumas limitações que poderão ser ultrapassadas em investigações posteriores.

A primeira prende-se com a especificidade da amostra do estudo, pois não se pode afirmar com toda a certeza que os nossos inquiridos realçaram, de facto, os principais constrangimentos a que estes profissionais estão sujeitos.

A dificuldade em aceder a dados estatísticos nacionais, ao seu registo e locais de trabalho, tornou também difícil o acesso aos TSST - pelo que a recolha de dados teve de ser feita online a fim de conseguir contactar um maior número de sujeitos. Tal impediu que se pudesse utilizar o INSAT em conformidade com o cenário definido na sua conceção, de modo a servir de suporte no âmbito de um diálogo do analista e dos trabalhadores. Ora este diálogo permitiria esclarecer e enriquecer alguns dos nossos dados e alcançar uma compreensão mais completa da atividade dos TSST. Mas a principal conclusão do nosso estudo é provavelmente que, apesar das especificidades resultantes da forma como se constituiu esta profissão em Portugal, algumas das suas caraterísticas são, na verdade, comuns às vivenciadas pelos profissionais da prevenção franceses (Atain-Kouadio et al, 2013) e brasileiros (Inoue \& Vilela, 2014): heterogeneidade de práticas (em relação à maior ou menor autonomia que referem ter para a realização do seu trabalho); problemas de reconhecimento (com possíveis impactos para a saúde); e necessidade de trocas com os pares (relacionadas com a necessidade de ajuda dos colegas). 
Estas questões apontam para a necessidade de se repensar o modo como estes profissionais são formados, inicialmente, mas ainda no âmbito de processos de formação contínua, pois são suscetíveis de fortalecer a criação de um género profissional (Garrigou \& Peissel-Cottenaz, 2013) propício à partilha, no coletivo, das regras efetivas e das dificuldades da profissão. Neste estudo ficou, pois, deveras claro que manter a vigilância, antecipando as situações que podem constituir um atentado à saúde dos trabalhadores, exige conhecimentos e competências que ultrapassam aquelas aprendidas num primeiro momento de formação mais generalista (Garrigou \& PeisselCottenaz, 2013).

\section{BIBLIOGRAFIA}

Amaro, A. D. (2013). A crise e os riscos psicossociais no âmbito de segurança e saúde no trabalho. In D. d. Coimbra, Riscos Naturais, Antrópicos e Mistos. Homenagem ao Professor Doutor Fernando Rebelo (pp. 569 - 584). Coimbra: Departamento de Geografia. Faculdade de Letras. Universidade de Coimbra.

Atain-Kouadio, J.-J., Clément, D., Dubois, Ph., Ghesquier, B., Mignot, G., Penel, Ph., Rocher, M., \& Schneider, R. (2013). La dynamique des retombées de la formation à l'ergonomie chez les professionnels de la prévention institutionnelle en France. In C. Teiger et M. Lacomblez (coord.). (Se) Former pour transformer le travail - Dynamiques de constructions d'une analyse critique du travail (pp. 308-328). Québec/ Bruxelles: Presses de l'Université Laval/PUL/ l'European Trade Union Institute/ETUI.

Carvalho, A. C. (2009). O stress ocupacional na docência universitária: modos de gestão da fronteira trabalho/ família. (Tese de Mestrado não publicada). Universidade do Porto, Porto.

Clot, Y. (2010). Trabalho e poder de agir. Belo Horizonte: Fabre- factum.

Coelho, J. M. (2009). Gestão Preventiva de Riscos Psicossociais no Trabalho em Hospitais no Quadro da União Europeia. Porto: Universidade Fernando Pessoa.

Costa, L. S. (2013). Riscos Psicossociais: O "Filho Pródigo" da Segurança e Saúde no Trabalho. Revista Segurança, 212, Ano XLVII, 16-21.

Costa, L. S. \& Santos, M. (2013). Fatores Psicossociais de Risco no Trabalho: Lições Aprendidas e Novos Caminhos. International Journal on Working Conditions, 39 - 58.

Cosme, J. (2006). As preocupações higio-sanitárias em Portugal (2 $2^{a}$ metade do século XIX e princípio do XX). Revista da Faculdade de Letras - História, III Série, 7, 181 - 195.

Duarte, F., Théry, L., \& Ullilen, C. (2016). Os equipamentos de proteção individual (EPI): Protetores, mas nem sempre. Apresentação do dossier. Laboreal, 12(1), 9-11. http://dx.doi.org/ 10.15667/laborealxii0116fd

Duarte, V. M. (2011). Avaliação de riscos psicossociais para a saú- de no trabalho: contributo de um estudo com enfermeiros. (Dissertação Mestrado não publicada). Viseu: Escola Superior de Viseu. http://hdl.handle.net/10400.19/1671 
Ferreira, A. B. (2015). Saúde no Trabalho: Uma Avaliação de Riscos Psicossociais numa empresa do ramo industrial". (Dissertação de Mestrado não publicada). Porto: Universidade Fernando Pessoa.

Garrigou, A. \& Peissel-Cottenaz, G. (2013). Une approche réflexive de l'activité des préventeurs et de leurs besoins en formation: une étude française. In C. Teiger et M. Lacomblez (coord.). (Se) Former pour transformer le travail - Dynamiques de constructions d'une analyse critique du travail (pp. 329- 350). Québec/Bruxelles: Presses de l'Université Laval/PUL/ l'European Trade Union Institute/ETUI.

Garrigou, A., Weill-Fassina, A., Brun, J.-P., Six, F., Chesnais, M., \& Cru, D. (1999). As Atividades dos Profissionais de Segurança: Uma Problemática Desconhecida. Anais do Congresso da ABERGO. Salvador, Bahia.

Gollac, M. \& Bodier, M. (2011). Mesurer les facteurs psychosociaux de risque au travail pour les maîtriser. Obtido de http://www.college-risquespsychosociaux-travail.fr/site/Rapport-CollegeSRPST.pdf

Graça, L. (2002). História da saúde e da segurança do trabalho na Europa. In Rui Veiga (revisão técnica de Fernando Cabral), Higiene, Segurança, Saúde e Prevenção de Acidentes de Trabalho (5 actualização)(Unidade 3, Capítulo 4).Lisboa: Verlag Dashöfer.

IDICT (2001). Manual de Certificação - Técnico Superior de Segurança e Higiene do Trabalho e Técnico de Segurança e Higiene do Trabalho.

Inoue, K. S. \& Vilela, R. A. (2014). O poder de agir dos Técnicos de Segurança do Trabalho: conflitos e limitações. Revista Brasileira de Saúde Ocupacional, 136-149. https://doi. org/ 10.1590/0303-7657000074613

Peeters, S. E., Duarte, F. J., Garrigou, A., Peissel-Cottenaz, G., Chabut, F., \& Lelles, S. (2003). Segurança do Trabalho: que trabalho é esse? XXII Encontro Nacional de Engenharia de Produção. Ouro Preto, Minas Gerais.

Rocha, A. S. (2012). Condições de trabalho e os efeitos na saúde no Núcleo de Infância e Juventude: uma análise por equipas de intervenção no território Porto-Gaia. (Dissertação de Mes- trado não publicada). Porto: Unversidade Católica do Porto.

\section{NOTAS}

1. O nível de concordância variou entre 1 (concordo total- mente) e 4 (discordo totalmente).

2. $\mathrm{M}<2$, inversão da lógica de leitura relativamente ao grau de incómodo).

3. A escala atribuída à resposta desta pergunta vai de 1 - "Muito boa" a 5 - "Muito má".

4. Agruparam-se as respostas obtidas em quatro grupos (de acordo com a representatividade dos inquiridos dentro destes grupos): "Lisboa"; "Norte"; "Centro"; e "Outros", onde se incluíram as sub-regiões “Algarve”, “Alentejo", “Região Autónoma dos Açores” e "Região Autónoma da Madeira".

5. Consideraram-se as respostas à questão sobre o setor de atividade da empresa segundo as divisões da CAE Rev. 3. Agruparam-se todas as divisões num único grupo que corresponde aos TSST internos/ comuns, à exceção da di- visão "Atividades de consultoria, científicas, técnicas e si- milares" que corresponde aos TSST externos. Este agrupa- mento resultou em 59 TSST internos/ comuns e 28 TSST externos, sendo que 14 inquiridos não responderam ou a sua resposta não permitiu a classificação segundo a CAE. 


\section{RESUMOS}

Alterações sociais e organizacionais têm trazido profundas transformações que podem gerar nos locais de trabalho, dinâmicas de cariz psicossocial que se tornam preocupantes. Os "riscos psicossociais" resultam de um conjunto de condições e de fatores intrínsecos à organização do trabalho que devem ser identificados. Este estudo teve como principal objetivo verificar se os Técnicos Superiores de Segurança no Trabalho (TSST) que desempenham a sua atividade em Portugal estão, ou não, expostos a fatores psicossociais de risco e se, como consequência, veem deteriorado o estado da sua saúde. Concluiu-se que estão expostos a fatores psicossociais de risco associados a condições e caraterísticas do seu trabalho. A sua saúde é percecionada como sendo boa e não muito relacionada com o trabalho, embora alguns dos seus problemas de saúde sejam agravados por ele. Quanto menos afetados são os TSST pelos fatores psicossociais de risco melhor percecionam a sua saúde.

Los cambios sociales y organizacionales han provocado profundas transformaciones y han generado en los entornos de trabajo, dinámicas de tipo psicosocial que pueden resultar preocupantes. Los llamados "riesgos psicosociales" resultan de un conjunto de condiciones y factores intrínsecos a la organización del trabajo que deben ser identificados. Este estudio tuvo como objetivo principal comprobar si los Técnicos Superiores de Seguridad en el Trabajo (TSST) que ejercen su actividad en Portugal están o no expuestos a este tipo de factores y si, en resultado de ello, su estado de salud se deteriora. El estudio concluye afirmando que si están expuestos a factores de riesgo psicosociales asociados con las condiciones y características de su trabajo. Su salud es percibida como buena y no muy relacionada con el trabajo, aun cuando aceptan el hecho de que algunos de sus problemas de salud se agravan por el mismo. Cuanto menos afectados están los TSST por factores de riesgo psicosociales, mejor perciben su salud.

Les changements sociaux et organisationnels produisent actuellement des transformations qui peuvent générer, sur le lieu de travail, des dynamiques de nature psychosociale préoccupantes. Les "risques psychosociaux" proviennent d'un ensemble de conditions et de facteurs propres à l'organisation du travail, qui doivent être identifiés. Cette étude a eu pour finalité principale de vérifier si les techniciens supérieurs de sécurité au travail (TSST) exerçant leur activité au Portugal sont, ou non, exposés à des facteurs psychosociaux de risque et si, en conséquence, ils constatent une dégradation de leur état de santé. On a conclu qu'ils sont effectivement exposés à des facteurs psychosociaux de risque, associés aux conditions et caractéristiques de leur travail. Ils perçoivent toutefois leur état de santé comme étant bon et sans rapport évident avec le travail, même s'ils admettent que certains problèmes de santé sont aggravés par ce même travail. Cependant, au moins ces TSST sont affectés par des facteurs psychosociaux, au mieux leur santé leur semble satisfaisante.

Social and organisational changes are causing deep transformations, which can generate quite concerning psychosocial dynamics in the work places. The "psychosocial risks" result from a set of conditions and factors inherent to the organisation of the work and it is important to identify them. This study's main purpose was to verify whether the Advanced Technicians on Occupational Health (ATOH) who perform their activity in Portugal are exposed, or not, to psychosocial risk factors and whether, consequently, their health condition is deteriorating. The findings show they are exposed to psychosocial risk factors related to the work conditions and characteristics. Their health is perceived as good and not entirely work-related, though some of their health problems are made worse by the work. The less the ATOH are affected by the psychosocial risk factors, the better do they perceive their health. 
ÍNDICE

Mots-clés: facteurs psychosociaux de risque, conditions de travail, activité, techniciens supérieurs de sécurité au travail, INSAT

Palabras claves: factores de riesgo psicosociales, condiciones de trabajo, actividad, Técnicos Superiores de Seguridad en el Trabajo, INSAT

Palavras-chave: fatores Psicossociais de Risco, condições de trabalho, atividade, Técnicos Superiores de Segurança no Trabalho, INSAT

Keywords: Psychosocial Risk Factors, Work conditions, Activity, Advanced Technicians on Occupational Safety, INSAT

\section{AUTORES}

JOANA F. RAMALHO

Escola Superior de Tecnologia da Saúde de Coimbra do Instituto Politécnico de Coimbra Apartado 7006, Rua 5 de Outubro São Martinho do Bispo 3046-854 Coimbra Portugal

jfframalho@gmail.com

\section{LÚCIA SIMÕES COSTA}

Escola Superior de Tecnologia da Saúde de Coimbra do Instituto Politécnico de Coimbra Apartado 7006, Rua 5 de Outubro São Martinho do Bispo 3046-854 Coimbra Portugal

lucias@estescoimbra.pt 